\title{
Patch Scale Nest-Site Selection by Marbled Murrelets (Brachyramphus
} marmoratus)

\section{Sélection du site de nidification à l'échelle de l'îlot chez le Guillemot marbré (Brachyramphus marmoratus)}

\author{
$\underline{\text { Michael P. Silvergieter }}^{1}$ and David B. Lank $^{1}$
}

\begin{abstract}
The Marbled Murrelet (Brachyramphus marmoratus) is a threatened alcid that nests almost exclusively in old-growth forests along the Pacific coast of North America. Nesting habitat has significant economic importance. Murrelet nests are extremely difficult and costly to find, which adds uncertainty to management and conservation planning. Models based on air photo interpretation of forest cover maps or assessments by low-level helicopter flights are currently used to rank presumed Marbled Murrelet nesting habitat quality in British Columbia. These rankings are assumed to correlate with nest usage and murrelet breeding productivity. Our goal was to find the models that best predict Marbled Murrelet nesting habitat in the ground-accessible portion of the two regions studied. We generated Resource Selection Functions (RSF) using logistic regression models of ground-based forest stand variables gathered at plots around 64 nests, located using radio-telemetry, versus 82 random habitat plots. The RSF scores are proportional to the probability of nests occurring in a forest patch. The best models differed somewhat between the two regions, but include both ground variables at the patch scale (0.2-2.0 ha), such as platform tree density, height and trunk diameter of canopy trees and canopy complexity, and landscape scale variables such as elevation, aspect, and slope. Collecting ground-based habitat selection data would not be cost-effective for widespread use in forestry management; air photo interpretation and low-level aerial surveys are much more efficient methods for ranking habitat suitability on a landscape scale. This study provides one method for ground-truthing the remote methods, an essential step made possible using the numerical RSF scores generated herein.
\end{abstract}

RÉSUMÉ. Le Guillemot marbré (Brachyramphus marmoratus) est un Alcidé menacé qui niche presque exclusivement dans les vieilles forêts de la côte nord-américaine du Pacifique. L'étude de son habitat de nidification exige des ressources financières importantes. En effet, les nids de guillemots sont très difficiles à trouver, de sorte que cette activité est coûteuse, conférant à la planification de l'aménagement et à la conservation un caractère incertain. Les modèles fondés sur des cartes du couvert forestier provenant de la photointerprétation ou encore sur des évaluations faites à partir de vols en hélicoptère à basse altitude sont actuellement utilisés pour classer l'habitat de nidification des Guillemots marbrés en ColombieBritannique en fonction de sa qualité présumée. Cette approche repose sur la présomption que ce classement est corrélé à l'occupation des nids et à la productivité des guillemots. L'objectif de cette étude était de déterminer les meilleurs modèles pour prévoir l'habitat de nidification des guillemots dans la partie accessible au sol des deux régions étudiées. Nous avons élaboré des fonctions de sélection des ressources (FSR) au moyen de modèles de régression logistique, à partir de variables de peuplements forestiers récoltées au sol dans 64 parcelles contenant un nid (localisé par radiotélémétrie) et dans 82 parcelles tirées aléatoirement. Les valeurs prévues par les FSR sont proportionnelles à la probabilité d'occurrence d'un nid dans un îlot forestier. Les meilleurs modèles différaient légèrement entre les deux régions, mais

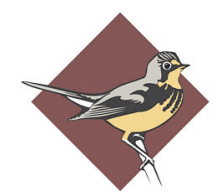

BIRD STUDIES CANADA 
comprenaient des variables à l'échelle de l'îlot (0,2-2,0 ha), comme la densité des arbres contenant une plateforme, la hauteur et le diamètre des arbres, et la complexité du couvert forestier, et des variables à l'échelle du paysage, comme l'altitude, l'orientation et la pente. La collecte au sol des données de sélection du site de nidification n'est pas rentable dans un contexte d'aménagement forestier à grande échelle; la photointerprétation et les relevés faits à partir de vols à basse altitude sont des méthodes beaucoup plus efficaces pour classer la qualité de l'habitat à l'échelle du paysage. En conclusion, cette étude offre une méthode de validation au sol des méthodes à distance, étape essentielle réalisée au moyen des valeurs numériques générées par les FSR.

Key Words: Brachyramphus marmoratus; habitat selection; Marbled Murrelet; nesting habitat; Resource Selection Functions

\section{INTRODUCTION}

The Marbled Murrelet (Brachyramphus marmoratus) is a northeastern Pacific seabird that utilizes coastal old-growth forest between southeast Alaska and central California for nesting habitat (Nelson 1997, Burger 2002). The species is classified as "threatened" under the Species at Risk Act in Canada, and southern populations have similar status under the Endangered Species Act in the United States, recently reconfirmed (USFWS 2009).

Marbled Murrelet nests are extremely difficult to locate, therefore knowledge of nesting habits and habitat selection relies upon a relatively small sample of confirmed nest sites. Nests are established primarily on platforms created by moss or duff on large branches of old-growth conifers (Hamer and Nelson 1995, Nelson 1997). Nests must be sufficiently high enough in the tree to allow for stall landings and drop-off takeoffs, and ideally adjacent to forest canopy gaps (see reviews by Burger 2002, McShane et al. 2004, Piatt et al. 2007). In British Columbia, these structures occur in stands at least 140 years old, and with a higher probability of occurrence in stands > 200 years (Burger 2002). Nests occur at low densities (Conroy et al. 2002) over extensive tracts of often steep inaccessible terrain.

About 180 nests have been confirmed to date in British Columbia. Partly because of the difficulty of locating nests across a large landscape, land managers and conservation biologists in British Columbia have developed remote methods of habitat assessment, including GIS algorithms, air photo interpretation, and low-level aerial surveys
(Burger et al. 2009a). The attributes scored by these methods at the forest patch scale $(\sim 0.2-2.0$ ha of similarly aged forest) rely on the scant ground data previously available from real nests, and audiovisual detections of behavior associated with nest sites ("occupied detection", Paton 1995), and modified with subsequent findings (Manley 1999, Chatwin 2002). These have been used to infer habitat associations, or selection, by comparing forest variables of occupied and unoccupied stands (Hamer 1995, Hamer and Nelson 1995 range-wide, Kuletz et al. 1995 for Alaska, Bahn and Newsom 2002a, Rodway and Regehr 2002 for Vancouver Island, Burger and Bahn 2004, Hamer et al. 2008 for Washington). Habitat quality inferences based on this method must be treated with some caution because actual nest sites are not identified and nest success is unknown. Occupied detections may include prospecting behavior, and be biased toward gaps or edges where detections are more likely (Burger et al. 2000, Rodway and Regehr 2002). However, Bahn and Newsom (2002b) compared nesting habitat indicators inferred from behavioral observations to mapped forest variables to create a habitat suitability model for Clayoquot Sound, which tested well against a sample of known nests from the same area (V. Bahn and D. B. Lank, personal communication). Manley (1999) used audio-visual detections and intensive ground surveys to locate a reasonably sized sample of real nests, and compared ground habitat variables at nest sites to those at random sites within the same patch.

Based on previous studies of habitat use (using occupied detections; Rodway and Reghr 2002, Hamer et al. 2008) and habitat selection and success at the patch level (using air photos; Waterhouse et al. 2004, 2008), five stand-level variables emerge 
as indicators of Marbled Murrelet nesting habitat in British Columbia: mean diameter at breast height $(\mathrm{DBH})$, density of canopy trees, density of potential platforms, density of trees with platforms, and canopy variation or complexity. At the landscape level, controlling for old-forest distributions, nests tend to be located at somewhat below average elevations (mean elevation at Desolation Sound: $748 \mathrm{~m}$ for nests, $840 \mathrm{~m}$ for old forest) on steeper slopes, and north aspects (Bradley 2002, Zharikov et al. 2006, 2007, Waterhouse et al. 2008). Waterhouse et al. (2008), in different analyses of the same data, found that nests at higher elevations and on steeper slopes had higher midfledging success. Landscape information can be easily obtained by remote methods, and habitat selection determined solely by landscape attributes is a tempting prospect for management.

Previous studies described differences in habitat between used and either nonused or random sites. Although this design allows for analysis of habitat selection (Jones 2001), quantitative models are needed to rank habitat based on probabilities of stand use, because presence is impractical to confirm for all possible areas. Because of the cost and logistics involved in accessing sites on the ground, we do not expect these methods to find widespread application. Rather, this study uses ground-based stand-level attributes from real nests and available sites to determine the relative importance of patch and landscape scales, and to provide a tool that may be used to help validate habitat suitability indices based on remote methods. We develop Resource Selection Functions (RSF; Manly et al. 2002) for ground-accessible landscapes in southern British Columbia. Our models are based on habitat characteristics measured on the ground at the largest sample of nest sites currently available for the species, comprising over $40 \%$ of the known nests in British Columbia, and comparing those to characteristics at random sites in the same regions, yielding probability of use for nesting at a site. The RSF scores we develop show how the probability of use changes with habitat variables, allowing us to answer the critical question of what murrelets select for in nesting habitat with greater certainty and detail than previous studies. For example, it is well established that forest stands utilized for nesting contain higher densities of platform trees than do random or unoccupied stands (Burger 2002). However, the shape of the relationship between platform density and probability of nesting has not been previously investigated because of lack of data from ground plots. The contribution of variables may be nonlinear, producing 'thresholds' that may be used to refine existing habitat suitability rankings based on remote methods.

\section{METHODS}

\section{Study areas}

We studied two regions on the southern coast of British Columbia, Canada, that support large populations of breeding Marbled Murrelets (Burger 2001, Hull et al. 2001): Clayoquot Sound (CS; $49^{\circ}$ $12^{\prime} \mathrm{N}, 126^{\circ} 06^{\prime} \mathrm{W}$ ) on the west coast of Vancouver Island and Desolation Sound (DS; $50^{\circ} 05^{\prime} \mathrm{N}, 124^{\circ}$ $40^{\prime} \mathrm{W}$ ) on the mainland (Fig. 1). Both regions are mountainous, with forest cover naturally fragmented by steep topography, fjords, and stream channels. Clayoquot Sound has a cooler and wetter maritime climate than DS, with mean summer (April-August) temperatures of $11.9^{\circ}$ and $13.4^{\circ} \mathrm{C}$, rainfall of 720 $\mathrm{mm}$ and $300 \mathrm{~mm}$, respectively. The regions also differ in their extent of old-growth forest loss, with over $80 \%$ loss of original old-growth forest cover at DS, compared with $25 \%$ loss at CS (Zharikov et al.2006). As a result, remaining old-growth forest at DS is fragmented and tends to occur in small patches. Fifty percent of the DS sites in this study occurred in forest patches smaller than $100 \mathrm{ha}$; by contrast, all of the CS sites were in patches larger than 100 ha, and many were in large contiguous tracts of old-growth forest. In both regions, human settlement is limited and habitat loss is mainly due to commercial logging.

\section{Data sources}

Nest habitat data were collected by ground crews at plots surrounding nest sites located by radio telemetry (Bradley 2002, Zharikov et al. 2006) at DS (1999-2001; $\mathrm{n}=43)$ and CS (2000-2002, $\mathrm{n}=$ 27). Many additional nests located (76 out of 121 at DS and 8 out of 36 at CS) were inaccessible because of steep terrain, geographic barriers, or lack of safe nearby helicopter landing spots. These sites could not be included in this study because ground habitat data were not available. Our results are thus most applicable to areas with comparable terrain, and should not be interpreted as reflecting ground conditions over the full range of nesting habitat used by murrelets in these regions. 
Fig. 1. Map of study regions in south coastal British Columbia. Circles = nest sites; triangles $=$ random sites.

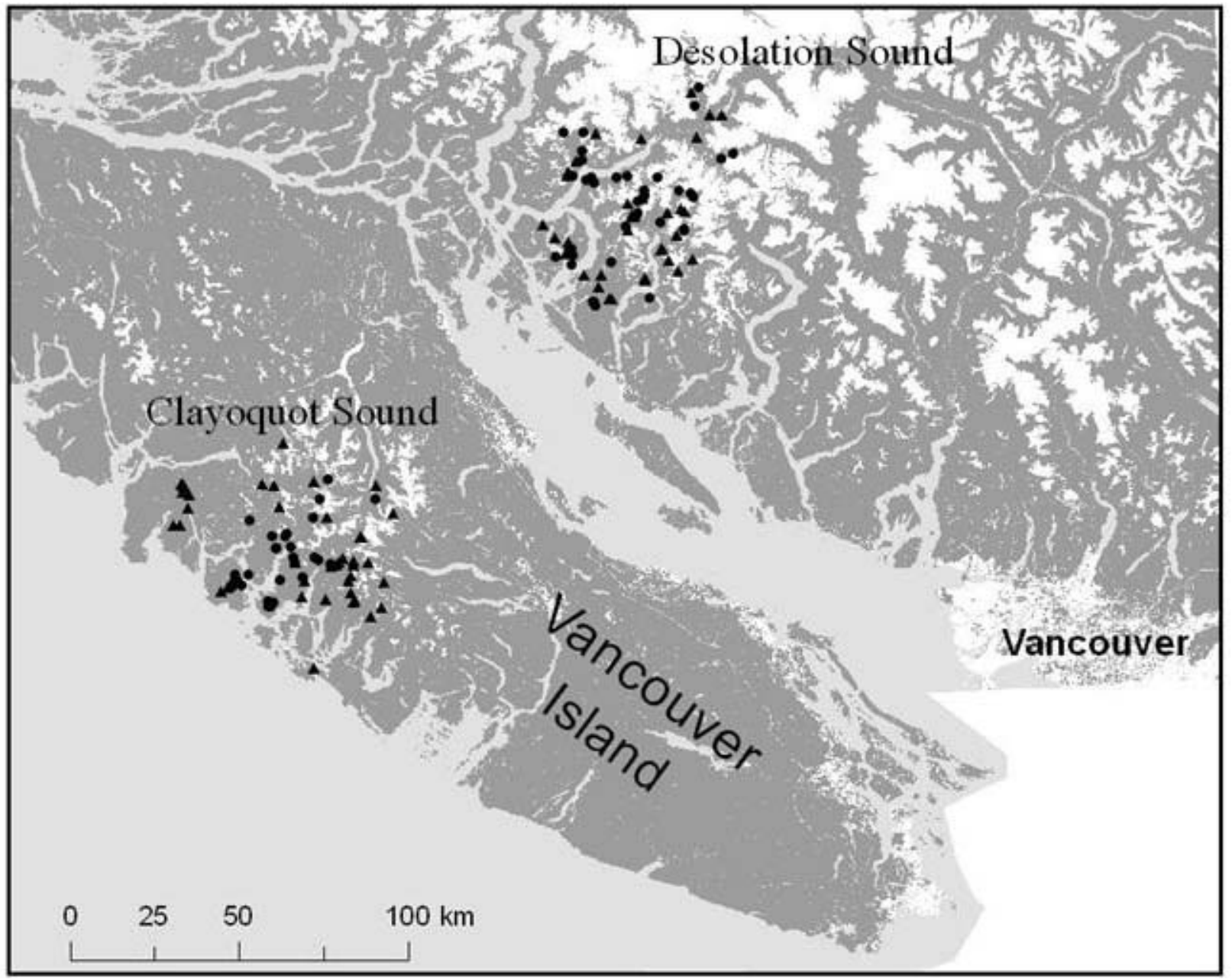

Locations of random habitat plots were selected a priori within old-growth forest ( $>140$ years) across the landscape defined by nest locations within each region (Zharikov et al. 2006). Ground crews sampled random plots using helicopter access, and as with nest sites, some preselected random plots were inaccessible.

At CS, additional ground plots were available from a separate dataset (Bahn and Newsom 2002a). Because these were not completely geographically randomized, we subsampled 19 sites stratified by valley location, with sample sizes selected such that the distribution of all CS random plots for valley location was similar to the distribution of nests at CS.

Two methods of ground vegetation survey were used in this study. "RIC" protocol (Resource Inventory Standards Committee 2001) was used at all ground accessible nests as well as some random plots $(\mathrm{n}=11$ at $\mathrm{DS})$. This method involves measuring stem diameter at breast height (DBH), tree height, potential nesting platforms, and mistletoe and epiphyte development in all trees (> $10 \mathrm{~cm} \mathrm{DBH})$ in a $25 \mathrm{~m}$ radius plot centered on the 
nest tree or a random tree in a randomly located plot (30 m x $30 \mathrm{~m}$ for Bahn's additional CS plots). Tree height was measured by clinometer for a few widely-spaced reference trees in the plot, and estimated for others.

Most random plots were sampled at CS (2001) and DS (2004) following the "SFU" protocols (F. H. Huettmann, unpublished manuscript), which consisted of subsampling canopy trees within a 75 $\mathrm{m}$ radius of the center. Species, DBH, and height were recorded for a randomly selected center tree and its three nearest canopy trees, as well as any canopy trees found in 12 three-meter radius plots situated on four radial arms (two running along the slope contour from the center, and two perpendicular to the slope) at $25 \mathrm{~m}$ intervals. Trees with at least one potential platform, i.e., platform trees, were counted in a $25 \mathrm{~m}$ (CS; similar to RIC protocol) or $75 \mathrm{~m}$ radius (DS).

\section{Variables}

We considered a set of variables based on the results of previous habitat use studies and their availability throughout the dataset (Table 1). ASPECT was categorized as: "north" (N, including north, west, and flat aspects) or "south" (S, including south and east aspects). North and west aspects receive less direct sunlight and more rainfall, because prevailing weather systems are from the west, and would therefore be expected to have a positive effect on murrelet nesting habitat in terms of epiphyte development. Data on epiphyte development were available from nest sites, ranked in four categories (Resource Inventory Standards Committee 2001). Epiphyte categories did not differ among trees on north vs. west aspects (Pearson chi-square test: $\chi^{2}$ $=2.49, \mathrm{df}=1, \mathrm{P}=0.12$ ), nor on south vs. east aspects $\left(\chi^{2}=0.31, \mathrm{df}=1, \mathrm{P}=0.58\right)$. Significantly more trees with higher epiphyte cover occurred on north/west aspects compared with south/east $\left(\chi^{2}=11.47, \mathrm{df}=\right.$ $1, P<0.01)$. Flat sites $(n=9)$ were grouped with north aspects because they occurred on valley bottoms, which tend to be wetter and more shaded.

We obtained SLOPE from Digital Elevation Maps (Integrated Land Management Bureau 2000) using the mean of the $25 \mathrm{~m} \mathrm{x} 25 \mathrm{~m}$ cell containing the site and its eight neighboring cells (Zharikov et al. 2006). Elevation was measured on the ground using GPS or altimeter.
We considered five ground-based patch-level variables in the model set $(\mathrm{CANDBH}, \mathrm{CANHT}$, CANCOMPL, DENCANSTEM, and DENPLATR; Table 1). Because only canopy trees were measured at random plots (SFU protocol), only these were represented in the first four variables. Previous studies (Bahn and Newsom 2002a, Rodway and Regehr 2002) found that canopy trees within the plot best predicted usage, and represent $94 \%$ of potential nesting trees in this dataset. In this study, canopy trees are the dominant and codominant trees in the patch. Potential nesting trees are reflected in the variable DENPLATR, the density of platform trees, including canopy and a small proportion of subcanopy trees. Because of differences in protocol, reliable data for this variable was not available for random plots at DS.

\section{Comparison of protocols}

Both SFU and RIC methods were used at a sample of 61 sites, to allow comparison. We assessed the comparability of variable values for CANDBH, CANHT, and DENCANSTEM, and DENPLATR. CANDBH, DENCANSTEM, and DENPLATR differed significantly (paired t-test; $\mathrm{P}<0.01$ ) between protocols. The mean difference for CANDBH (RIC-SFU mean $-7 \mathrm{~cm} \pm 1.9 \mathrm{SE}$ ), however, did not seem biologically significant compared to the range of 34-166 cm (mean $80 \mathrm{~cm}$ ) and $34-142 \mathrm{~cm}$ (mean $87 \mathrm{~cm}$ ) for RIC and SFU protocols, respectively. Though statistically significant, the authors were comfortable that a difference of $7 \mathrm{~cm}$ did not represent an important habitat difference, and was likely less than the field measurement error, considering the challenging terrain in which these measurements were taken. Differences for DENCANSTEM were large (RICSFU mean -29.5 trees/ha \pm 9.0 ) and biologically significant. This variable was also correlated with $\mathrm{CANDBH}$, and for these reasons was dropped from further consideration.

DENPLATR was significantly lower under SFU protocol (RIC-SFU mean: 28.8 platform trees/ha $\pm 3.7)$. We suspect this is because of the difference in plot sizes and the difficulty of viewing platforms in any trees within a $75 \mathrm{~m}$ radius. DENPLATR was therefore not included for analyses at DS, but was retained at CS.

A small number of trees were measured at some sites, particularly with SFU protocol. Subsampling 
Table 1. Description of variables used for habitat selection modeling.

\begin{tabular}{lccc}
\hline \hline Variable Name & Description & Units of measurement & Scale \\
\hline REGION & Desolation Sound or Clayoquot Sound & CS/DS & \\
ASPECT & Slope aspect (North $=226^{\circ}-45^{\circ}$; South $\left.=46^{\circ}-225^{\circ}\right)$ & $\mathrm{N} / \mathrm{S}$ & Landscape \\
SLOPE & Slope, from Digital Elevation Model & ${ }^{\circ}$ (Degrees) & Landscape \\
ELEVATION & Elevation (meters) measured on the ground & $\mathrm{m}$ & Landscape \\
CANDBH & Mean DBH (Diameter at Breast Height) of & $\mathrm{cm}$ & Patch \\
canopy trees & Mean height of canopy trees & Patch \\
CANHT & Canopy complexity (standard deviation of & $\mathrm{m}$ & Patch \\
CANHT) & Density of canopy trees (all species & \# per hectare & Patch \\
DENCANSTEM & Density of platform trees (trees with at least one & \# petential nest platform) & Patch \\
\hline
\end{tabular}

of the above mentioned sites showed that habitat measures for the plot were not significantly different when five or more trees were measured. For this reason we retained sites containing at least five canopy trees; those with fewer were excluded from our analyses.

\section{Data analysis}

We used logistic regression models with the binary response variable NEST (nest/random) to generate RSFs. We built a priori models with plausible combinations of measured habitat variables to predict probability of nesting, and used an information-theoretic approach to select the best model(s) among the alternative candidate set (Burnham and Anderson 2002).

The regions included in this study differ in both climate and degree of fragmentation, factors that may affect habitat selection by murrelets (Tranquilla et al. 2005, Zharikov et al. 2006, 2007). A combined model set including REGION and regional interaction terms (Table 2) strongly supported the hypothesis that relationships differed between regions (Table 3a). Given regional interactions, we applied the model set $1-4$ plus 9 and 10 to CS and DS separately, to develop more regionspecific RSFs. This approach also permitted the use of DENPLATR as a variable in the CS model set (models 5-8).

To simplify the model set, we included or excluded landscape and patch-level variables as sets (Table 2). Support for landscape-level variables alone (Model 1) would suggest that patch-scale variables measured by ground-based observers are less important. Support for patch-level variables alone (Models 2, 5, 7, 9) would indicate selection at the forest patch level is most important. However, DENPLATR was included separately, for the CS region, because of its importance in previous studies (Manley 1999, Rodway and Regehr 2002). All combinations of these variable-groups were tested in the model set, as well as a null model (intercept only) that tests only the mean and variation inherent in the response variable. Support for the null model would indicate that variables other than those tested are responsible for variation observed. For combined regions, three additional models included a quadratic term for CANHT and CANCOMPL to reflect the hypothesis of a nonlinear relationship for these variables (models 9-11). The result is eight 
Table 2. The model set used to predict probability of nesting based on ground habitat variables. Variables were grouped according to the scale involved.

\begin{tabular}{|c|c|}
\hline & Model \\
\hline $1^{\dagger, \pm, \S}$ & $\mathrm{ASPECT}+\mathrm{ELEV}+\mathrm{SLOPE}$ \\
\hline $2^{\dagger, \pm, \&}$ & CANDBH + CANHT + CANCOMPL \\
\hline $3^{\dagger, \S}$ & CANDBH + CANHT + CANCOMPL + ASPECT + ELEV + SLOPE \\
\hline $4^{\dagger, \S}$ & (Null) \\
\hline $5^{+}$ & DENPLATR \\
\hline $6^{\ddagger}$ & DENPLATR + ASPECT + ELEV + SLOPE \\
\hline $7^{+}$ & DENPLATR + CANDBH + CANHT + CANCOMPL \\
\hline 8 & DENPLATR + CANDBH + CANHT + CANCOMPL + ASPECT + ELEV + SLOPE \\
\hline $9^{\dagger}$ & $\mathrm{CANDBH}+\mathrm{CANHT}+\mathrm{CANCOMPL}+\mathrm{CANHT}^{\wedge} 2+\mathrm{CANCOMPL}^{\wedge} 2$ \\
\hline $10^{\dagger}$ & $\mathrm{CANDBH}+\mathrm{CANHT}^{+} \mathrm{CANCOMPL}+\mathrm{CANHT}^{\wedge} 2+\mathrm{CANCOMPL}^{\wedge} 2+\mathrm{ASPECT}+\mathrm{ELEV}+\mathrm{SLOPE}$ \\
\hline $11^{\dagger}$ & REGION + ASPECT + ELEV + SLOPE + REGION*ASPECT REGION*ELEV REGION*SLOPE \\
\hline $12^{\dagger}$ & $\begin{array}{l}\text { REGION + CANDBH + CANHT + CANCOMPL + REGION*CANDBH REGION*CANHT + REGION* } \\
\text { CANCOMPL }\end{array}$ \\
\hline $13^{\dagger}$ & $\begin{array}{l}\text { REGION + CANDBH + CANHT + CANCOMPL + REGION*CANDBH + REGION*CANHT + REGION* } \\
\text { CANCOMPL + ASPECT + ELEV + SLOPE + REGION*ASPECT + REGION*ELEV + REGION*SLOPE }\end{array}$ \\
\hline $14^{\dagger}$ & $\begin{array}{l}\text { REGION + CANDBH + CANHT + CANCOMPL + } \text { CANHT }^{2}+\text { CANCOMPL }^{2}+\text { REGION*CANDBH }^{*}+ \\
\text { REGION*CANHT + REGION*CANCOMPL + REGION*CANHT }{ }^{2}+\text { REGION }^{*} \text { CANCOMPL }^{2}+\text { ASPECT + } \\
\text { ELEV + SLOPE + REGION*ASPECT + REGION*ELEV + REGION*SLOPE }\end{array}$ \\
\hline $15^{\dagger}$ & $\begin{array}{l}\text { REGION + CANDBH + CANHT + CANCOMPL + } \text { CANHT }^{2}+\text { CANCOMPL }^{2}+\text { REGION }^{*} \text { CANDBH }^{2}+ \\
\text { REGION } * \text { CANHT + REGION } * \text { CANCOMPL + REGION } * \text { CANHT }^{2}+\text { REGION }^{*} \text { CANCOMPL }^{2}\end{array}$ \\
\hline
\end{tabular}

models applied to CS, four models applied to DS, and 11 models applied to the combined set.

We checked for multicolinearity using the Variable Inflation Factor (VIF) in PROC REG (SAS Institute Inc. 2003), whereby a value $>10$ could indicate a problem (Neter et al. 1996). VIFs indicated little multicolinearity, with values $<3$ for all variables in both CS and DS.
Sample sizes were relatively small (DS $\mathrm{n}=72 ; \mathrm{CS}$ $\mathrm{n}=70$ ), so we used Akaike's Information Criterion for small sample sizes $\left(\mathrm{AIC}_{c}\right)$. The global model for $\mathrm{CS}$ indicated over dispersion $(\mathrm{c}=1.44$, respectively), so the Quasi-Likelihood AIC $\left(\mathrm{QAIC}_{c}\right.$ ) was used for that model set (Burnham and Anderson 2002). We consider models in which $\mathrm{AIC}_{c}$ values differ from the best-fitting model by $\leq$ 2 (AIC ; $_{c}$ Burnham and Anderson 2002) as well as 
Table 3. Ranking of the top four models for each region, with predictive performance of the top-ranked and averaged models. Models with significant support $(\Delta \leq 2$; Burnham and Anderson 2002) are in bold.

a) Combined

\begin{tabular}{|c|c|c|c|c|c|c|c|c|}
\hline Model \# & $\mathrm{K}^{\dagger}$ & $\mathrm{AIC}_{c}^{\dagger}$ & $\Delta^{\S}$ & $w_{i}^{!}$ & $\mathrm{R}^{2 \pi}$ & \multicolumn{3}{|c|}{ Predictive Performance ${ }^{\#}$} \\
\hline & & & & & & $>0.5$ & $>0.65$ & $>0.8$ \\
\hline 13 & 14 & 173.43 & 0.00 & 0.89 & 0.42 & 75 & 52 & 27 \\
\hline 12 & 8 & 179.55 & 6.03 & 0.04 & 0.28 & - & - & - \\
\hline 9 & 6 & 180.10 & 6.67 & 0.03 & 0.24 & - & - & - \\
\hline
\end{tabular}

b) Clayoquot Sound (CS)

\begin{tabular}{|c|c|c|c|c|c|c|c|c|}
\hline Model \# & $\mathrm{K}^{\dagger}$ & $\mathrm{QAIC}_{c}^{\dagger \dagger}$ & $\Delta^{\S}$ & $w_{i}^{l}$ & $\mathrm{R}^{2 \pi}$ & \multicolumn{3}{|c|}{ Predictive Performance $^{\#}$} \\
\hline & & & & & & $>0.5$ & $>0.65$ & $>0.8$ \\
\hline 8 & 8 & $\mathbf{5 7 . 8 0}$ & 0.00 & 0.56 & 0.55 & 78 & 52 & 44 \\
\hline 7 & 5 & 59.66 & 1.85 & 0.22 & 0.38 & 78 & 41 & 15 \\
\hline 2 & 4 & 61.17 & 3.37 & 0.10 & 0.45 & - & - & - \\
\hline \multirow[t]{2}{*}{3} & 7 & 62.66 & 4.88 & 0.05 & 0.27 & - & - & - \\
\hline & & & & \multicolumn{2}{|c|}{ Averaged Model } & 78 & 56 & 26 \\
\hline \multicolumn{9}{|c|}{ c) Desolation Sound (DS) } \\
\hline \multirow[t]{2}{*}{ Model \# } & $\mathrm{K}^{\dagger}$ & $\mathrm{AIC}_{c}^{\ddagger}$ & $\Delta^{\S}$ & $w_{i}^{l}$ & $\mathrm{R}^{2 \pi}$ & \multicolumn{3}{|c|}{ Predictive Performance ${ }^{\#}$} \\
\hline & & & & & & $>0.5$ & $>0.65$ & $>0.8$ \\
\hline 3 & 7 & 92.98 & 0.00 & 0.54 & 0.36 & 78 & 54 & 27 \\
\hline 2 & 4 & 93.38 & 0.40 & 0.44 & 0.25 & 65 & 43 & 16 \\
\hline 1 & 4 & 100.62 & 2.19 & 0.01 & 0.36 & - & - & - \\
\hline \multirow[t]{2}{*}{4} & 1 & 101.81 & 8.83 & 0.01 & - & - & - & - \\
\hline & & & & \multicolumn{2}{|c|}{ Averaged Model } & 78 & 49 & 13 \\
\hline
\end{tabular}

${ }^{\dagger}$ Number of parameters, including intercept.

\$ Akaike’s Information Criterion, corrected for small sample sizes.

$\S$ Increase in AIC over the best model.

I Akaike weight, the relative support for the model within the set.

II Nagelkerke's R² (Nagelkerke 1991).

${ }^{\#}$ For best and averaged models only; Predictive performance $=\%$ sites with RSF score $>\mathrm{x}$.

$\dagger$ Quasi-likelihood Akaike's Information Criteria, corrected for small sample sizes and over dispersion. 
$\mathrm{AIC}_{w}$, which indicated relative support for a model from among a set of candidate models.

\section{Model and parameter performance and analysis}

In region-specific model sets, multiple models received significant support from $\mathrm{AIC}_{c}$. We therefore obtained parameter estimates through model averaging, in which each model contributes according to its Akaike weight (Burnham and Anderson 2002). Because we were most interested in model performance, we tested the performance of both $\mathrm{AIC}_{c}$-selected models and averaged models in predicting nest sites. The same data set was used for testing because we did not have an independent data set with confirmed nest sites, nor was the original data set large enough to warrant setting aside data for testing. We report the proportion of nests sites that were assigned RSF scores $>0.5$, > 0.65 , and $>0.8$ (where the RSF score represents probability of nesting).

To assess the effect of individual ground variables on probability of use, a set of simulated data points were created, wherein each continuous variable was varied at equal intervals across the feasible range for that variable, with all other variables held constant at their mean value for all random sites. Predicted probabilities of nesting and 95\% confidence intervals were generated using the SCORE statement in PROC LOGISTIC (SAS Institute Inc. 2003) based on the model fit for the best model in each region. This produces a curve indicating the predicted probability of nesting throughout the range of the variable.

\section{RESULTS}

\section{Ground habitat plots}

Habitat selection models were created using 142 sites: 27 nest sites and 43 random sites at CS, and 37 nests and 35 random sites at DS. Sites at DS were located at elevations ranging from 5 to $1210 \mathrm{~m}$, with more than $50 \%$ between 300 and $600 \mathrm{~m}$. CS sites ranged from 0 to $1200 \mathrm{~m}$, with most between 300 and $900 \mathrm{~m}$. Slopes ranged from 3 to $58^{\circ}$. About $60 \%$ of both nest and random sites at CS were classified as "north" aspect compared with $76 \%$ of nests and $48 \%$ of random sites at DS.

The variables considered here differ with respect to nest/random sites, as well as between regions (Table 4). Of special note is the surprising result for canopy height at CS, where trees at random sites were taller than those at nest sites. This contrasts with the DS sample, as well as the results of numerous previous studies (summarized in Burger 2002).

In univariate logistic models, CANHT and CANCOMPL showed significant regional interactions (for both: Wald chi-square $=12.6, \mathrm{df}=1, \mathrm{p}<0.01$ ). All other variables available for both regions did not have significant regional interactions.

\section{Model selection}

The best models predicting nesting habitat selection differed among the three model sets (Table 3). The combined regions model set includes quadratic expressions for canopy height and canopy complexity as well as regional interaction terms. Patch variables occur in two of the models, landscape in one, and the quadratic term in one of the models. Model 13, with landscape and patch variables as well as regional interaction received significant support with an AIC-weight $\left(w_{i}\right)$ of 0.89 .

For CS, models 8 and 7 were the best supported, with a cumulative $w_{i}$ of 0.78 . Model 8 is the global model, whereas model 7 excludes landscape variables. Patch variables appear in each of the top four models (Table $3 b$ ). There was very little support for model 1 (delta-AIC > 7), which includes landscape-level factors only.

For DS, models 3 and 2 collectively account for $72 \%$ of the total $w_{i}$ in the model set (Table 3c). These two models both include patch variables, with one model including landscape variables and the other not. Model 1 (landscape only) again receives very weak support (delta-AIC $\left.>7, w_{i}=0.01\right)$. 
Table 4. Mean and 95\% confidence intervals for continuous variables included in models.

\begin{tabular}{|c|c|c|c|c|c|c|c|}
\hline \multirow[t]{2}{*}{ Variable } & \multirow[t]{2}{*}{ Region } & \multicolumn{3}{|c|}{ Nest } & \multicolumn{3}{|c|}{ Random } \\
\hline & & $\mathrm{n}$ & Mean & $95 \% \mathrm{CI}$ & $\mathrm{n}$ & Mean & $95 \% \mathrm{CI}$ \\
\hline \multirow[t]{2}{*}{$\operatorname{ELEV~(m)~}$} & $\mathrm{CS}$ & 27 & 501 & $378-625$ & 43 & 536 & $449-624$ \\
\hline & DS & 37 & 430 & $359-501$ & 35 & 512 & $388-635$ \\
\hline \multirow[t]{2}{*}{ SLOPE $\left(^{\circ}\right)$} & $\mathrm{CS}$ & 27 & 30.8 & $25.4-36.4$ & 43 & 23.0 & $19.4-26.6$ \\
\hline & DS & 37 & 29.5 & $25.4-33.6$ & 35 & 26.1 & $21.6-30.6$ \\
\hline \multirow[t]{2}{*}{ CANDBH $(\mathrm{cm})$} & $\mathrm{CS}$ & 27 & 79.8 & $74.6-84.9$ & 43 & 72.4 & $66.8-77.9$ \\
\hline & DS & 37 & 78.1 & $71.0-85.3$ & 35 & 69.6 & $63.7-75.6$ \\
\hline \multirow[t]{2}{*}{ CANHT (m) } & $\mathrm{CS}$ & 27 & 33.4 & $31.1-35.7$ & 43 & 37.6 & $35.2-40.0$ \\
\hline & DS & 37 & 36.7 & $35.2-38.2$ & 35 & 33.0 & $30.9-35.0$ \\
\hline \multirow[t]{2}{*}{ CANCOMPL (m) } & $\mathrm{CS}$ & 27 & 4.9 & $3.9-5.8$ & 43 & 6.0 & $5.3-6.6$ \\
\hline & DS & 37 & 6.9 & $6.2-7.7$ & 35 & 5.0 & $4.3-5.8$ \\
\hline \multirow{2}{*}{$\begin{array}{l}\text { DENPLATR } \\
\text { (trees/ha) }\end{array}$} & $\mathrm{CS}$ & 27 & 57.2 & $47.5-66.8$ & 43 & 36.4 & $23.6-49.2$ \\
\hline & DS & - & - & - & - & - & - \\
\hline
\end{tabular}

\section{Model analysis}

Because multiple models for each region received support from both AIC, we obtained parameter estimates through model averaging (Burnham and Anderson 2002). The resulting models had much lower predictive performance than any of the original models (Table 3 ) and were therefore not considered further.

The averaged model for each region model set performed nearly as well as the best performing models at the two lower thresholds, but scored less than $60 \%$ as many nests $>0.8$ than did the original models. The averaged models also had larger $95 \%$ confidence intervals for parameter estimates. We use predictive performance, particularly at the highest threshold to distinguish the best predictive model. Based on these criteria, we select as the top model the global models for each region: model 13 for both regions combined, model 8 at CS, and model 3 at DS.

Figure 2 indicates the effects of single variables on RSF scores. For patch variables, density of trees with platforms, available for CS only, shows a clear nonlinear trend, with the increase in probability of use slowing markedly at densities greater than 100 (Fig. 2a). This is equal to approximately 20 to 25 platform trees in a $25 \mathrm{~m}$ hectare plot. Although CANDBH shows a more or less positive trend with use in both regions, CANHT produces opposite trends at CS and DS. Probability of use decreases sharply in CS forests taller than about $40 \mathrm{~m}$, whereas DS has a less positive trend. CANCOMPL shows a weakly negative trend at CS, a strong positive effect 
at DS, and an increasing trend for the combined regions, with a slight dip at intermediate values due to the quadratic function.

Among the topographic variables, slope has a positive effect on probability of use in all three top models, with the strongest effect at CS. Probability of use decreases with elevation at CS, although it has a weakly positive relationship at DS.

\section{DISCUSSION}

\section{Resource selection functions}

This research is the first to create Resource Selection Functions (RSFs) based on ground habitat plots from known Marbled Murrelet nests. In southern British Columbia, models including both patch and landscape scale predictors were the best models. Model 1, containing only landscape-scale variables received minimal support in region-specific model sets, and had lower predictive performance compared with other top-ranked models for both regions combined, indicating that significant predictive ability is lost when habitat selection models do not include patch-scale variables.

The test of an RSF should be its predictive ability. Unfortunately, there were no suitable independent sets of known nest sites with habitat plots from the regions included in this study. One approach might have been to test models from DS against nests at CS (cf. Zharikov et al. 2007), but the limited size of our dataset and strong regional interactions precluded doing so. Instead, we tested the ability of the models to predict nest sites. If RSF scores are proportional to the probability of use, nest sites would typically have high RSF scores from a good predictive model. Random sites, which may have contained nests, are not diagnostic of model performance.

We considered a limited number of ecologically relevant models for this study to avoid an unacceptably large model set. Patch and landscape variables were considered as sets, although some of these variables may not be important in the final models. Excluding one of these variables within a group does not provide any advantage in terms of data acquisition for future applications of these models. Although ground variables are difficult to obtain, the high cost and logistics are involved in accessing the site; once there, the savings realized by eliminating one or more of these variables would be negligible or nonexistent.

\section{Accessibility bias}

At DS, a larger proportion of all nests $(\sim 40 \%)$ found by radio-telemetry were inaccessible by ground compared with CS. Using landscape variables available for all nests, F. H. Huettmann, E. Cam, D. B. Lank, R. W. Bradley, L. Lougheed, N. Parker, L. McFarlane Tranquilla, C. Lougheed, Y. Zharikov, P. P.-W. Yen, and F. Cooke (personal communication) concluded that inaccessible sites tended to be on steeper slopes and at lower-mid elevations, which could create a bias in habitat selectivity studies based on ground accessible nests only. Accessibility was often based on factors outside the plot itself, such as steep terrain distance between the nearest access point and the plot.

As stated earlier, our results apply to the portion of the landscape that is accessible on the ground. If the patch-scale variables measured here covary with geographic parameters that affect accessibility, our RSFs may not represent the entire local landscapes used by nesting Marbled Murrelets. However, the habitat where our models are directly applicable is representative of that most available for commercial logging, and therefore of most immediate conservation concern.

\section{Comparison of regions}

Significant differences exist between the two study areas considered here in terms of climate, logging history, and current habitat availability and fragmentation, as well as availability of platform density data for this study. Models including regional interactions received the strongest support, as expected, because CANHT and CANCOMPL had opposite effects at CS compared with DS. Thus, with respect to ground variables at least, regional modeling of habitat preferences will provide better predictability.

Each of the top models at CS included density of platform trees, a variable that was not available at DS. The next highest ranked models at CS that do not include density of platform trees are the top two models at DS (models 2 and 3). Density of platform trees is an important factor affecting murrelet nesting choices in CS. Unfortunately, the absence 
Fig. 2. Plots of the Resource Selection Functions (RSF) Score (predicted probability of nesting) derived from the top model for each region, showing the effect of a single variable, with all other predictor variables held constant. a) density of platform trees b) DBH of canopy trees c) canopy height d) canopy complexity e) elevation f) slope. Grey lines indicate 95\% confidence intervals; dashed lines = Clayoquot Sound $(\mathrm{CS})$; solid lines $=$ Desolation Sound $(\mathrm{DS})$.
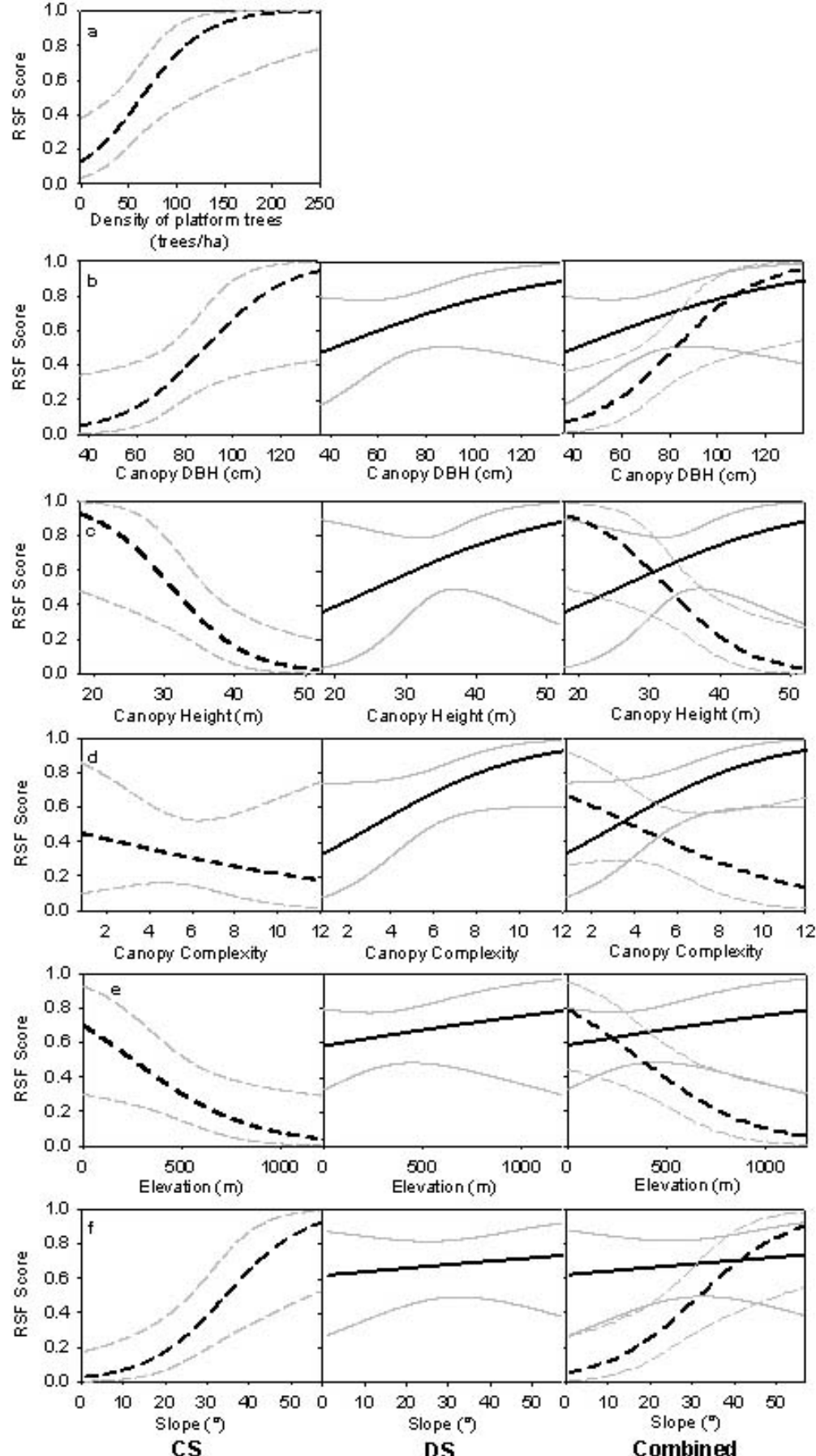
of similar data for DS prevents us from making inferences for that region. Differing degrees of harvest have resulted in smaller contiguous patches of old-growth forest at DS, which may affect habitat selection decisions with regard to platform density (Silvergieter 2009).

Model 13 for the combined data set is adequate at predicting nest sites in both regions, with $41 \%$ of nest sites at DS and 53\% of nest sites at CS having an RSF score $\geq 0.7$ (Fig. 3). For the region-specific models, $59 \%$ of nest sites at CS and $64 \%$ of those at DS had an RSF score higher than 0.7 (Fig. 3). The combined model, as expected, is not as good as region-specific models for describing habitat in those regions. The real benefit to a combined model would be in extending to other regions of the coast, an application that is limited by regional interactions. The highest ranked combined model that did not include regional interactions was model $3\left(\mathrm{AIC}_{w}<0.01\right)$, that scored $27 \%$ of DS nests scored higher than 0.7 , and only $15 \%$ of CS nests.

A single RSF thus does not describe habitat selection nearly as well as region-specific models. Previous studies at CS and DS that concentrated on a larger scale found differences in habitat selection between the two regions (Zharikov et al. 2006, Waterhouse et al. 2009). Specific to our data, opposing trends seen in canopy height and the omission of platform data may account for the difference, or it may be due to real differences in climate, forest harvest, or other features (Zharikov et al. 2006).

Previous habitat selection studies using this set of nests have failed to find strong selectivity at CS (Waterhouse et al. 2008) or had less predictive power (Waterhouse et al. 2009) than at DS. It has been inferred that most habitat available at CS is suitable for nesting and that consequently, murrelets there are less "choosy." The random habitat plots used in this study suggest this is not the case. Platform trees, an essential component of nesting habitat, were absent in 10/43 (23\%) of random sites at CS. There is also an apparent preference for shorter trees at CS, a finding contrary to previous research.

\section{Density of platform trees}

Figure 3 indicates that the relationship of DENPLATR to the probability of nesting is nonlinear. The probability of nesting levels off at the upper edge of the range of platform tree densities. This relationship is of particular interest for management because the forests with highest value for logging are also prime murrelet habitat, often characterized by the largest trees that tend to contain more platforms (W. Wall, D. Marquis, D. Lindsay, D. Byng, personal communication). A ranking of platform availability is a substantial component of current habitat ranks based on lowlevel aerial surveys. This curve is also biologically significant. A minimum of one platform tree is a fundamental requirement of any potential nesting habitat, but habitat use studies have consistently identified higher densities of platform trees as a characteristic of nest sites (Burger 2002). This is somewhat puzzling because murrelets are known to nest at low densities (Burger 2002, Conroy et al. 2002). Researchers have thus argued that higher densities of nesting platforms at the forest stand level are unlikely to support a proportionally higher density of nests (e.g., Burger and Waterhouse 2009). Our asymptotic curve is consistent with this argument for higher platform densities. At lower densities, multiple potential nest sites may increase the likelihood of finding a higher quality site, confer advantages by diluting predator search efficiency ("multiple nest site hypothesis"; Martin 1993, Chalfoun and Martin 2009), or allow reuse of the same high quality patch without reusing an old nest known to predators (Burger et al. 2009b). Despite these possibilities, although the sample size is not large, platform tree density did not correlate with measures of nesting success in this dataset (Silvergieter 2009).

\section{Other variables}

The diameter of canopy tree stems (CANDBH), although not likely to confer any direct advantage to nesting murrelets, is correlated with stand age (Bahn and Newsom 2002a). Older trees are more likely to develop larger and more abundant platforms, which may in turn affect nest success: nestlings and eggs are less likely to fall from larger platforms, and predator search efficiency may be 
Fig. 3. A greater percentage of nest sites within each region have higher Resource Selection Functions (RSF) scores (predicted probability of nesting), compared with random sites for the best model for: a) Clayoquot Sound (random = white, nest = dark. grey); (b) Desolation Sound (random = light grey, nest $=$ black); and (c) Combined regions.
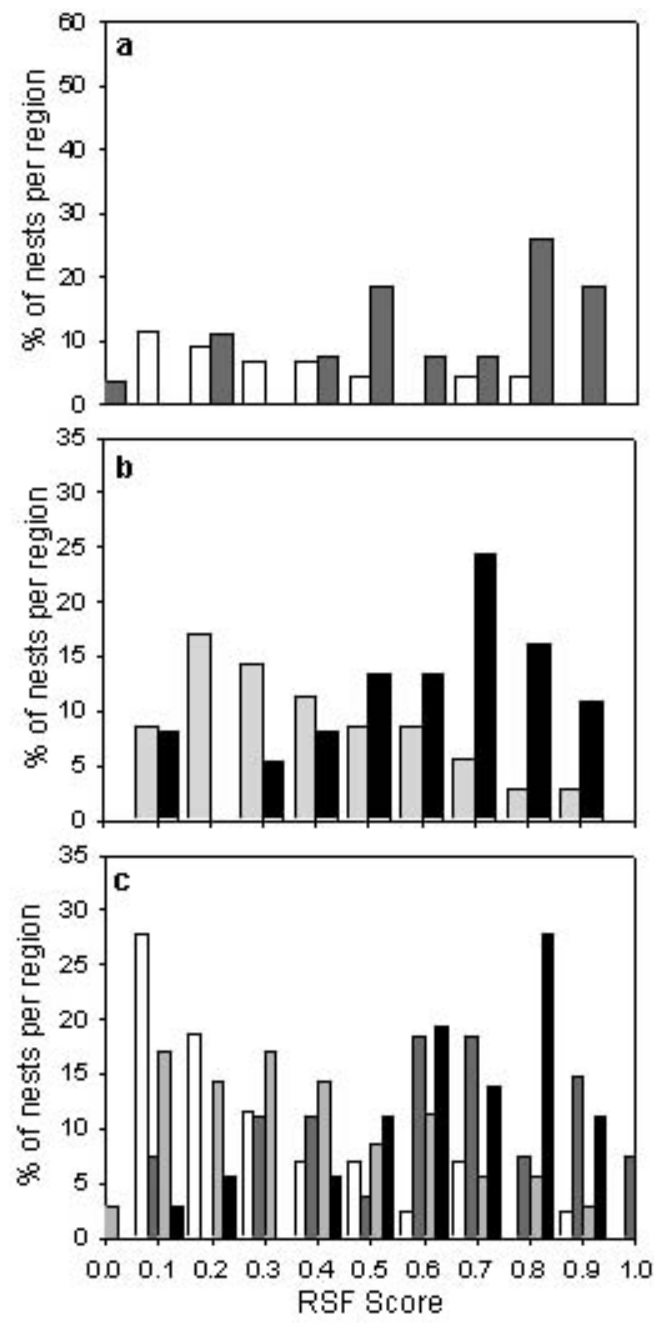

reduced with more potential nesting platforms (Martin 1993, Chalfoun and Martin 2009).

Canopy height appears to have opposite effects at DS and CS. At DS, overall canopy height of nest patches was taller than random patches, though the negative effect of this variable within the model was not significant. At CS, random patches were taller than nest patches; Figure 3 indicates a strong decline in probability of nesting canopy height at CS. Some random sites at CS had extraordinarily tall trees that were underrepresented at nest sites. The absolute heights of trees utilized at CS are typical of those at DS and reported in previous work in the region (Manley 1999, Burger 2002). Canopy height does not appear to be a limiting factor within old-growth forests at CS; just $11 \%$ of random sites were shorter than the minimum height at nest patches. The quadratic term in the model for both regions results in a peak probability of nesting for forest patches around $30 \mathrm{~m}$ tall. A lower suitability of very tall forests has not been found in previous research, and should be viewed with caution. Studies consistently find that nest trees are among the tallest within a 
patch (Manley 1999, Conroy et al. 2002, Silvergieter and Lank 2011).

Canopy complexity has been found to be an important indicator of habitat selection in previous studies (e.g., Waterhouse et al. 2002, Hamer et al. 2008) although methods of estimating the variable vary among studies. Canopy complexity in our study reflects overall complexity of a $25 \mathrm{~m}$ radius plot, and it did not have a consistently strong effect in any models and was not a significant factor in the CS and combined models. Complexity may be correlated with other factors not available in remote analyses, such as nest cover (Grenier and Nelson 1995, Hamer and Nelson 1995) and epiphyte growth (Bahn and Newsom 2002b). Canopy complexity may offer improved canopy accessibility (Hamer and Nelson 1995, Burger 2002), though overall complexity across the plot may not be strictly necessary because access is only needed for a nest in a single tree.

Overall, inference for landscape variables in this study should be taken in the context of the accessibility bias discussed above. Preference for steeper slopes may provide accessibility advantages and preferred nesting possibilities (Fig. 2f) although the strength of the effect differs between CS and DS. Using the complete dataset not limited by accessibility bias, Zharikov et al. (2006) found a preference for steeper slopes, and Bradley et al. (2004) noted that nest success was higher on steeper slopes. Results for elevation also differ between regions (Fig. 2e). These results reflect previously existing ambiguous results (see Burger 2002) with respect to these aspects of murrelet nesting habitat selection. Our models show that landscape variables in conjunction with ground variables are an important component of Marbled Murrelet habitat selection, but their specific contribution is perhaps better studied with other methods.

\section{Management implications}

The ground variables of significance in previous studies, based on inferred nest sites (Hamer 1995, Rodway and Regehr 2002) proved useful descriptors of nesting habitat in this study, providing support for their continued use in management applications. The shapes of relationships with particular variables, controlling for other factors, as shown in Figure 3, can be used to refine interpretations of these variables in habitat ranking schemes. In our dataset, the best fitting habitat selection models differ between Clayoquot Sound and Desolation Sound, suggesting that regionspecific models will have greater utility.

The models supported here apply directly to oldgrowth forests at Clayoquot Sound and Desolation Sound accessible to humans on the ground. Nonetheless, they provide predictions for habitat use across a spectrum of habitat conditions. The topographical stratum represented by this study corresponds to that most strongly impacted by conventional forestry operations, and thus the results should be most applicable to such areas of operational interest. Note, however, that nests in "inaccessible" areas may be affected in future with use of more expensive helicopter logging or other approaches.

Our results indicate that a multiscale approach to understanding nesting habitat selection by Marbled Murrelets is warranted. Though habitat information at the landscape scale is more easily obtained and models apply to larger areas regardless of accessibility, landscape-only models in this study received little support compared with models that incorporated patch scale variables measured on the ground. Acquiring ground habitat information is extremely costly. More efficient methods of assessing nesting habitat quality using air photo interpretation and low-level aerial surveys have been developed and tested (Waterhouse et al. 2002, 2004, 2008, 2009). These methods are part of current management guidelines in the province and are used to rank habitat on a six-point scale. One of the primary questions that remain regarding this system is the relative suitability of each category rank, particularly the two highest quality ranks (Burger and Waterhouse 2009). Ground-based habitat selection models can be used to validate these remote methods. For instance, relative numbers of potential nesting platforms, a key requirement of nesting habitat and an important component of RSF models at Clayoquot Sound, cannot be quantitatively measured by remote methods. This study assigns a relative probability of nesting for any site for which certain ground data are available, which can be compared with the habitat quality rank assigned to those sites by remote methods. A proper treatment of this comparison is outside the scope of this paper, but Silvergieter (2009) provides such a treatment using habitat selection models similar to those presented here. 
Silvergieter (2009) also found that fledging success was independent of habitat selection described here. This simplifies management considerations because habitat selection, which is easier to measure than habitat productivity, should be a sufficient basis for decision making in terms of its relative impact on nesting murrelet productivity. Marbled Murrelets share a limited and commercially valuable landscape with logging interests in British Columbia. This study is a step toward improving land use decisions for conservation of murrelet nesting habitat.

Responses to this article can be read online at:

http://www.ace-eco.org/vol6/iss2/art6/responses/

\section{Acknowledgments:}

R. Ydenberg, A. Burger, A. Salomon, L. Waterhouse, and an anonymous referee provided for valuable comments on this paper. Carl Schwarz provided statistical advice. Fred Cooke, F.H. Huettmann initiated the nest study and we thank all those who collected habitat data, including Jason van Rooyen, Camila Morcos, and Hana Hermaniuk, and E\&B Helicopters for field support. MS was supported by the Centre for Wildlife Ecology, a Simon Fraser University Graduate Fellowship and a NSERC$C R D$ grant was awarded to DBL. Research was funded by the British Columbia Forest Science Program, Forest Investment Account, BC Timber Sales, and an NSERC-CRD grant that included Weyerhaeuser Canada Ltd., Cascadia Forest Products Ltd., Western Forest Products Inc., Terminal Forest Products Ltd., CANFOR Corp., and Island Timberlands LP as contributing industrial partners.

\section{LITERATURE CITED}

Bahn, V., and D. Newsom. 2002a. Can Marbled Murrelet use of nesting habitat be predicted from mapped forest characteristics? Pages 89-99 in A. E. Burger and T. A. Chatwin, editors. Multi-scale studies of populations, distribution and habitat associations of Marbled Murrelets in Clayoquot Sound, British Columbia. Ministry of Water, Land and Air Protection, Victoria, British Columbia, Canada. [online] URL: http://www.env.gov.bc.ca/wld/ documents/techpub/mamuwebs.pdf
Bahn, V., and D. Newsom. 2002b. Habitat suitability mapping for Marbled Murrelets in Clayoquot Sound. Pages 101-119 in A. E. Burger and T. A. Chatwin, editors. Multi-scale studies of populations, distribution and habitat associations of Marbled Murrelets in Clayoquot Sound, British Columbia. Ministry of Water, Land and Air Protection, Victoria, British Columbia, Canada. [online] URL: http://www.env.gov.bc.ca/wld/docu ments/techpub/mamuwebs.pdf

Bradley, R. W. 2002. Breeding ecology of radiomarked Marbled Murrelets (Brachyramphus marmoratus) in Desolation Sound, British Columbia. Thesis, Simon Fraser University, Burnaby, British Columbia, Canada.

Bradley, R. W., F. Cooke, L. W. Lougheed, and W. S. Boyd. 2004. Inferring breeding success through radiotelemetry in the Marbled Murrelet. Journal of Wildlife Management 68:318-331. http://dx.doi.org /10.2193/0022-541X(2004)068[0318:IBSTRI]2.0.CO;2

Burger, A. E. 2001. Using radar to estimate populations and assess habitat associations of Marbled Murrelets. Journal of Wildlife Management 65:696-715. http://dx.doi.org/10.2307/3803021

Burger, A. E. 2002. Conservation assessment of Marbled Murrelets in British Columbia: a review of the biology, populations, habitat associations, and conservation. Technical Report Series 387, Pacific and Yukon Region, Canadian Wildlife Service, Environmental Conservation Branch, Delta, British Columbia, Canada. [online] URL: http://www.sfu.ca/biology/wildberg/bertram/mamurt/ PartA.pdf

Burger, A. E., and V. Bahn. 2004. Inland habitat associations of Marbled Murrelets on southwest Vancouver Island, British Columbia. Journal of Field Ornithology 75:53-66.

Burger, A. E., V. Bahn, and A. R. M. Tillmanns. 2000. Comparison of coastal fringe and interior forests as reserves for Marbled Murrelets on Vancouver Island. Condor 102:915-920. http://dx.d oi.org/10.1650/0010-5422(2000)102[0915: COCFAI] 2.0.CO;2

Burger, A. E., I. A. Manley, M. Silvergieter, D. B. Lank, K. M. Jordan, T. D. Bloxton, and M. G. Raphael. 2009b. Re-use of nest sites by Marbled 
Murrelets (Brachyramphus marmoratus) in British Columbia. Northwestern Naturalist 90(3):217-226. http://dx.doi.org/10.1898/NWN08-50.1

Burger, A. E., and F. L. Waterhouse. 2009. Relationships between habitat area, habitat quality, and populations of nesting Marbled Murrelets. Journal of Ecosystems and Management 10:101-112. [online] URL: http://www.forrex.org/publications/jem/ ISS50/vol10 no1 art10.pdf

Burger, A. E., F. L. Waterhouse, A. Donaldson, C. Whittaker, and D. B. Lank. 2009a. New methods for assessing Marbled Murrelet nesting habitat: air photo interpretation and low-level aerial surveys. Journal of Ecosystems and Management 10:4-14. [online] URL: http://www.forrex.org/publications/jem/ $\underline{\text { ISS50/vol10 no1 art2.pdf }}$

Burnham, K. P., and D. R. Anderson. 2002. Model selection and multimodel inference: a practical information-theoretic approach. Springer-Verlag, New York, New York, USA.

Chalfoun, A. D., and T. E. Martin. 2009. Habitat structure mediates predation risk for sedentary prey: experimental tests of alternative hypotheses. Journal of Animal Ecology 78:497-503. http://dx.d oi.org/10.1111/j.1365-2656.2008.01506.X

Chatwin, T. A. 2002. Management of Marbled Murrelet nesting habitat in Clayoquot Sound. Pages 139-157 in A. E. Burger and T. A. Chatwin, editors. Multi-scale studies of populations, distribution and habitat associations of Marbled Murrelets in Clayoquot Sound, British Columbia. Ministry of Water, Land and Air Protection, Victoria, British Columbia, Canada. [online] URL: http://www.env. gov.bc.ca/wld/documents/techpub/mamuwebs.pdf

Conroy, B., V. Bahn, M. S. Rodway, L. Ainsworth, and D. Newsom. 2002. Estimating nest densities for Marbled Murrelets in three habitat suitability categories in the Ursus Valley, Clayoquot Sound. Pages 121-137 in A. E. Burger and T. A. Chatwin, editors. Multi-scale studies of populations, distribution and habitat associations of Marbled Murrelets in Clayoquot Sound, British Columbia. Ministry of Water, Land and Air Protection, Victoria, British Columbia, Canada. [online] URL: http://www.env.gov.bc.ca/wld/documents/techpub/ mamuwebs.pdf
Grenier, J. L., and S. K. Nelson. 1995. Marbled Murrelet habitat associations in Oregon. Pages 191-204 in C. J. Ralph, J. G. L. Hunt, M. G. Raphael, and J. F. Piatt, editors. Ecology and conservation of the Marbled Murrelet. General Technical Report PSW-GTR-152, Pacific Southwest Research Station, U.S. Forest Service, Albany, California, USA. [online] URL: http://www.fs.fed.us/psw/pub lications/documents/psw gtr152/psw gtr152 chap19. pdf

Hamer, T. E. 1995. Inland habitat associations of Marbled Murrelets in western Washington. Pages 163-176 in C. J. Ralph, J. G. L. Hunt, M. G. Raphael, and J. F. Piatt, editors. Ecology and conservation of the Marbled Murrelet. General Technical Report PSW-GTR-152, Pacific Southwest Research Station, U.S. Forest Service, Albany, California, USA. [online] URL: http://www.fs.fed.us/psw/pub lications/documents/psw gtr152/psw gtr152 chap17. pdf

Hamer, T. E., and S. K. Nelson. 1995. Characteristics of Marbled Murrelet nest trees and nesting stands. Pages 69-82 in C. J. Ralph, J. G. L. Hunt, M. G. Raphael, and J. F. Piatt, editors. Ecology and conservation of the Marbled Murrelet. General Technical Report PSW-GTR-152, Pacific Southwest Research Station, U.S. Forest Service, Albany, California, USA. [online] URL: http://www.fs.fed. us/psw/publications/documents/psw gtr152/ psw gtr152 chap06.pdf

Hamer, T. E., D. E. Varland, T. L. McDonald, and D. Meekins. 2008. Predictive model of habitat suitability for the marbled murrelet in western Washington. Journal of Wildlife Management 72:983-993. http://dx.doi.org/10.2193/2006-565

Hull, C. L., G. W. Kaiser, C. Lougheed, L. Lougheed, S. Boyd, and F. Cooke. 2001. Intraspecific variation in commuting distance of Marbled Murrelets (Brachyramphus marmoratus): ecological and energetic consequences of nesting further inland. Auk 118:1036-1046. http://dx.doi.or g/10.1642/0004-8038(2001)118[1036:IVICDO]2.0. $\mathrm{CO} ; 2$

Integrated Land Management Bureau. 2000. TRIM1 Data. Government of British Columbia, Victoria, British Columbia, Canada. [online] URL: http://arc hive.ilmb.gov.bc.ca/crgb/products/mapdata/ corporate watershed base products.htm 
Jones, J. 2001. Habitat selection studies in avian ecology: a critical review. Auk 118:557-562. http:// dx.doi.org/10.1642/0004-8038(2001)118[0557:HSSIAE] 2.0.CO;2

Kuletz, K. J., D. K. Marks, N. L. Naslund, N. J. Goodson, and M. B. Cody. 1995. Inland habitat suitability for the Marbled Murrelet in southcentral Alaska. Pages 141-150 in C. J. Ralph, J. G. L. Hunt, M. G. Raphael, and J. F. Piatt, editors. Ecology and conservation of the Marbled Murrelet. General Technical Report PSW-GTR-152, Pacific Southwest Research Station, U.S. Forest Service, Albany, California, USA. [online] URL: http://www.fs.fed. us/psw/publications/documents/psw gtr152/ psw gtr152 chap15.pdf

Manley, I. A. 1999. Behaviour and habitat selection of Marbled Murrelets nesting on the Sunshine Coast. Thesis, Simon Fraser University, Burnaby, British Columbia, Canada.

Manly, B., L. McDonald, D. L. Thomas, T. L. McDonald, and W. P. Erickson. 2002. Resource selection by animals. Kluwer, Boston, Massachusetts, USA.

Martin, T. E. 1993. Nest predation and nest sites: new perspectives on old patterns. Bioscience 43:523-532. http://dx.doi.org/10.2307/1311947

McShane, C., T. Hamer, H. R. Carter, G. Swartzman, V. L. Friesen, D. G. Ainley, R. Tressler, S. K. Nelson, A. E. Burger, L. B. Spear, T. Mohagen, R. Martin, L. A. Henkel, K. Prindle, C. Strong, and J. Keany. 2004. Evaluation report for the 5 year status review of the Marbled Murrelet in Washington, Oregon and California. Prepared for the U.S. Fish and Wildlife Service, Region 1, Portland, Oregon, USA. [online] URL: http://www. fws.gov/arcata/es/birds/MM/documents/ mm5yr rpt final web.pdf

Nagelkerke, N. J. D. 1991. A note on the general definition of the coefficient of determination. Biometrika 78:691-692. http://dx.doi.org/10.1093/b iomet/78.3.691

Nelson, S. K. 1997. Marbled Murrelet (Brachyramphus marmoratus). No. 276 in A. Poole, and F. Gill, editors. The Birds of North America. The Academy of Natural Sciences, Philadelphia, Pennsylvania, and The American Ornithologists' Union, Washington, D.C., USA.
Neter, J., M. H. Kutner, C. J. Nachtsheim, and W. Wasserman. 1996. Applied linear statistical models. Irwin, Chicago, Illinois, USA.

Paton, P. W. C. 1995. Marbled Murrelet inland patterns of activity: Defining detections and behavior. Pages 113-116 in C. J. Ralph, J. G. L. Hunt, M. G. Raphael, and J.F. Piatt, editors. Ecology and conservation of the Marbled Murrelet. General Technical Report PSW-GTR-152, Pacific Southwest Research Station, U.S. Forest Service, Albany, California, USA.

Piatt, J. F., K. J. Kuletz, A. E. Burger, S. A. Hatch, V. L. Friesen, T. P. Birt, M. L. Arimitsu, G. S. Drew, A. M. A. Harding, and K. S. Bixler. 2007. Status review of the Marbled Murrelet (Brachyramphus marmoratus) in Alaska and British Columbia. U.S. Geological Survey Open Report 2006-1387, USGS, Reston, Virginia. [online] URL: http://pubs.usgs.gov/ of/2006/1387/

Resource Inventory Standards Committee. 2001. Inventory methods for Marbled Murrelets in marine and terrestrial habitats. Version 2.0 Resource Inventory Committee, Victoria, British Columbia, Canada. [online] URL: http://archive.ilmb.gov.bc.ca/ risc/pubs/tebiodiv/murrelet2k1/mamu\%20ml20.pdf

Rodway, M. S., and H. M. Regehr. 2002. Inland activity and forest structural characteristics as indicators of Marbled Murrelet nesting habitat in Clayoquot Sound. Pages 57-87 in A. E. Burger and T. A. Chatwin, editors. Multi-scale studies of populations, distribution and habitat associations of Marbled Murrelets in Clayoquot Sound, British Columbia. Ministry of Water, Land and Air Protection, Victoria, British Columbia, Canada. [online] URL: http://www.env.gov.bc.ca/wld/docu ments/techpub/mamuwebs.pdf

SAS Institute Inc. 2003. SAS 9.1 For Windows. Cary, North Carolina, USA.

Schafer, J. L. 1997. Analysis of incomplete multivariate data. Chapman and Hall, London, UK. http://dx.doi.org/10.1201/9781439821862

Silvergieter, M. P. 2009. Multi-scale analyses of nest site selection and fledging success by Marbled Murrelets (Brachyramphus marmoratus) in British 
Columbia. Thesis, Simon Fraser University, Burnaby, British Columbia, Canada.

Silvergieter, M. P., and D. B. Lank. 2011. Marbled murrelets select distinctive nest trees within oldgrowth forest patches. Avian Conservation and Ecology 6(2): 3. http://dx.doi.org/10.5751/ACE-00 $\underline{462-060203}$

Tranquilla, L. M., N. R. Parker, R. W. Bradley, D. B. Lank, E. A. Krebs, L. Lougheed, and C. Lougheed. 2005. Breeding chronology of Marbled Murrelets varies between coastal and inshore sites in southern British Columbia. Journal of Field Ornithology 76:357-367.

U.S. Fish and Wildlife Service (USFWS). 2009. Marbled Murrelet (Brachyramphus marmoratus): 5-year review. Washington Fish and Wildlife Office, Lacey, Washington, USA. [online] URL: http://ecos.fws.gov/docs/five year review/doc2417. pdf

Waterhouse, F. L., R. Bradley, J. Markila, F. Cooke, and L. Lougheed. 2002. Use of airphotos to identify, describe, and manage forest structure of Marbled Murrelet nesting habitat at a coastal British Columbia site. Technical Report TR-016, BC Ministry of Forest and Range, Vancouver Forest Region, Nanaimo, British Columbia, Canada. [online] URL: http://www.for.gov.bc.ca/rco/research/ wildlifereports/tr016.pdf

Waterhouse, F. L., A. E. Burger, D. B. Lank, N. Parker, P. K. Ott, E. A. Krebs, and N. Parker. 2009. Using the low-level aerial survey method to identify Marbled Murrelet nesting habitat. Journal of Ecosystems and Management 10:80-96.

Waterhouse, F. L., A. Donaldson, D. B. Lank, P. K. Ott, and E. A. Krebs. 2004. Using airphotos to interpret Marbled Murrelet nesting habitat in British Columbia: application of a preliminary classification scheme. Technical Report TR-029, BC Ministry of Forest and Range, Vancouver Forest Region, Nanaimo, British Columbia, Canada. [online] URL: http://www.for.gov.bc.ca/rco/research/ Mamu/tr029.pdf

Waterhouse, F. L., A. Donaldson, D. B. Lank, P. K. Ott, and E. A. Krebs. 2008. Using air photos to interpret quality of Marbled Murrelet nesting habitat in south coastal British Columbia. Journal of Ecosystems and Management 9:17-37. [online]
URL: http://www.forrex.org/publications/jem/ISS47/ vol9 no1 art3.pdf

Zharikov, Y., D. B. Lank, and F. Cooke. 2007. Influence of landscape pattern on breeding distribution and success in a threatened alcid, the Marbled Murrelet: model transferability and management implications. Journal of Applied Ecology 44:748-759. http://dx.doi.org/10.1111/j.13 65-2664.2007.01319.x

Zharikov, Y., D. B. Lank, F. Huettmann, R. W. Bradley, N. Parker, P. P.-W. Yen, L. A. McFarlaneTranquilla, and F. Cooke. 2006. Habitat selectivity and breeding success in a forest-nesting alcid, the Marbled Murrelet, in two landscapes with different logging histories in British Columbia, Canada. Landscape Ecology 21:107-120. http://dx.doi.org/1 $\underline{0.1007 / \mathrm{s} 10980-005-1438-5}$ 